\title{
A Novel Low Profile Rectangular Microstrip Patch Antenna for L-Band Applications Using High Permittivity Substrate
}

\author{
GULZAR AHMAD*, ASIF SULTAN*, TARIQULLAH JAN*, MAJID ASHRAF*, AND MUHAMMAD SARIM** \\ RECEIVED ON 08.05.2018 ACCEPTED ON 20.10.2018
}

\begin{abstract}
A novel low-profile and miniaturized patch antenna on a substrate material of high dielectric constant has been designed, fabricated and tested in an indigenous laboratory. It is highly important to reduce the size of patch antenna as it limits the reduction of the sizes of the devices using this antenna. A number of techniques have been given for the size reduction of patch such as DGS (Defected Ground Structure), use of fractals and the use of metamaterials but in this paper the technique of high permittivity substrate has been implemented. The substrate as well as this conventional antenna has been prepared locally in Pakistan.A ceramic material of chemical composition $\left\{\left(\mathrm{Sr}_{0.5} \mathrm{~Pb}_{0.25} \mathrm{Ca}_{0.25}\right)-\mathrm{Tio}_{3}-3 \mathrm{Bi}_{2} \mathrm{O}_{3} . \mathrm{TiO}_{2}\right\}$ having a high dielectric constant has been used in the substrate of the antenna. The fabricated prototype was investigated experimentally for important parameters using Vector Network analyzer. The total measure of the antenna is $20.5 \times 26.5 \times 1.5 \mathrm{~mm}^{3}$. The antenna presented a large bandwidth of $186 \mathrm{MHz}(1070-1256$ MHz) in L-Band with a Return Loss of $21.10 \mathrm{~dB}$ at resonance. The VSWR (Voltage Standing Wave Ratio) remained under the standard value of 2 in the whole operating range. The proposed antenna may be employed in GPS (Global Positioning System) devices, Amateur Radio, Terrestrial Mobile Communication, Aeronautical and Maritime Mobile and other Military and Low Earth Orbit Satellite Communications.
\end{abstract}

Key Words: Low Profile, High Permittivity, Global Positioning System, L-Band, Maritime, Aeronautical.

\section{INTRODUCTION}

1 ntenna is a vital part of radio frequency transmitter or receiver. Antenna, commonly a mechanical structure is used to transmit or receive radio waves [1]. Microstrip Patch Antenna due to its inherent attractive properties has drawn the attention of antenna researchers and designers for past many years. Present day's smart wireless communication equipment has made it essential that antenna to be integrated in such devices should be of low profile [2]. Microstrip antennas are planar structures having three layers, central substrate layer and metallic radiating patch on its one side and a large metal ground on its other side [3] as displayed in Fig. 1 [4]. The patch and ground are conducting materials like copper, silver or gold while the substrate is a dielectric insulator. The radiations from the patch antenna are due to fringing fields from the edges of the Patch as depicted in Fig. 2 [5].

\footnotetext{
Authors E-Mail: (gulzar@uetpeshawar.edu.pk, tariqullahjan@uetpeshawar.edu.pk majid@uetpeshawar.edu.pk, engr_asif23@hotmail.com, msarim@fuuast.edu.pk)

* Department of Electrical Engineering, University of Engineering \& Technology, Peshawar, Pakistan.

** Department of Computer Science, Federal Urdu University of Arts, Science \& Technology, Karachi, Pakistan.
}

This is an open access article published by Mehran University Research Journal of Engineering and Technology, Jamshoro under the CC by 4.0 International License. 
The patch may be printed on the substrate using printed circuit board technology. The patch pattern may be of any shape, however some common shapes are as shown in Fig. 3 [7]. Numerous feeding techniques are available to couple EM energy to the patch antenna; among them are contacting and non-contacting methods [8]. Many models have been suggested to analyze patch antenna in which transmission line model is the most common model [9]. The main distinguished features of patch antennas are small size, low weight, conformability to different shapes and curvatures, easy fabrication and easy integration with printed electronic circuits [10]. However, patch antennas inherently suffer from small bandwidth low gain and comparatively large size at low frequencies [11]. Extensive research in past years has been dedicated to overcome these shortcomings. Many useful techniques have been proposed to enhance bandwidth [12] and increase gain [13]. In today's scenario of smart devices era size reduction of the patch

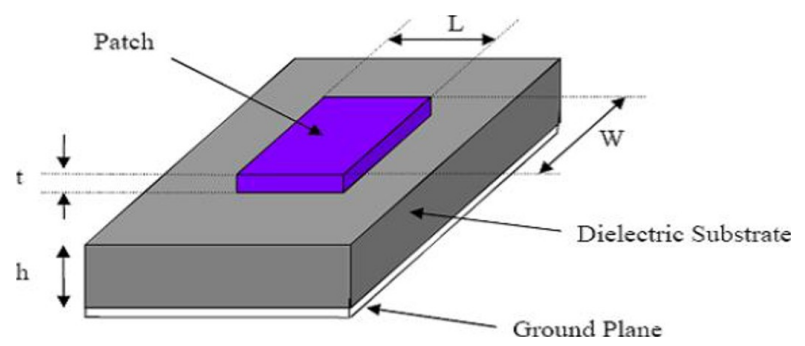

FIG. 1. CONVENTIONAL FORM OF A MICROSTRIP ANTENNA [5]

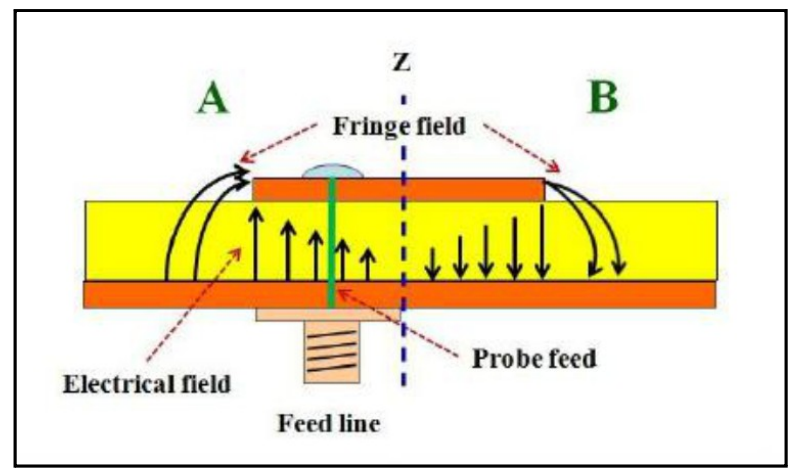

FIG. 2. FRINGING FIELDS OF PATCH ANTENNA [6] antenna is becoming a hot issue. The antenna size is proportional to the wavelength of designed frequency. Hence the size reduction at lower frequency is more critical. In past, a lot of work has been done for achieving miniaturization of patch antenna. Different techniques have been suggested like implementing defected ground structure [14], implementing slots in patch [15], use of shorting pins [16], use of high permittivity substrates [17] and introduction of parasitic patches [18]. Use of dielectric with high constant is very fruitful mechanism for achieving size reduction [19]. The same concept has been worked on in this paper. A ceramic material whose chemical composition is mentioned in the abstract has been implemented in this design. Firstly, all constituents were mixed proportionally to their weight. The powder format material was then mixed for many hours in a ball mill machine. Pellets were prepared shaped in a dye of required format using a high-pressure press machine. The pellets were sintered in high temperature furnace giving a stay at $1300 \mathrm{C}$ for 3 hours. The sintered items were then cleaned and polished to final shape using grinding machine. The material has very high dielectric constant and it has drastically reduced the antenna size at the desired frequency.

It has been described in [20] that the structure and dimensions of the antenna changes the output
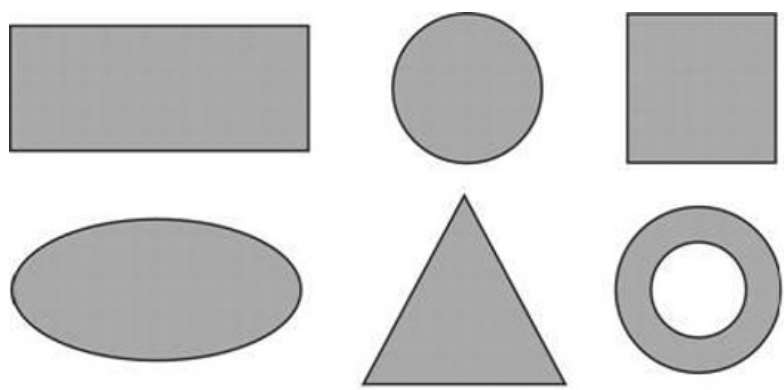

FIG. 3. DIFFERENT PLANS OF PATCH [7]

Mehran University Research Journal of Engineering \& Technology, Volume 38, No. 4, October, 2019 [p-ISSN: 0254-7821, e-ISSN: 2413-7219] 
performance. In addition, the permittivity of the substrate material plays a crucial role in antenna's characteristics. The increase in the dielectric constant results in the decrease of the resonant frequency as well as the bandwidth of the antenna. So the creation and selection of this high dielectric substrate has given us the desired frequency in the $\mathrm{L}$ band and the bandwidth in a promising bandwidth of $186 \mathrm{MHz}$.

Rakholiya and Langhnoja [21] elaborate different mechanisms of the size reduction of patch antenna that include the size reduction using Meta materials, creation of defects in the patch, creation of slots in the ground creation of pins between ground and patch and finally using materials having high dielectric constants. The pros and cons of all the above mentioned mechanisms are summarized as follows:

Using Meta materials for the goal of achieving higher miniaturization result in lower bandwidth and poor efficiency. This mechanism was avoided in this research as it degrades the efficiency of the antenna.

Introducing slots in the patch can reduce the size and improves the bandwidth but on the other hand it results in poor polarization and secondly the structure becomes very complex.

The introduction of pins between ground and patch is cost effective but it has no standard procedure.

A reasonable size reduction can be obtained using dielectric substrates with high dielectric constants but it is expensive and limits the bandwidth of the antenna.
So some researchers are of the opinion that these materials are costly and as this material has been prepared locally so it is cost effective. Secondly the material that has been used in this design has a reasonable bandwidth.

A miniaturized significant gain triple band patch antenna of antenna size $(31.25 \times 37.05 \times 0.762 \mathrm{~mm})$ has been demonstrated in [22] and it has larger size than the proposed antenna in this paper.

Ali et. al. [23] has mentioned a microstrip patch antenna which has a size of $65 \times 56 \mathrm{~mm}$ and its center frequency is $960 \mathrm{MHz}$. Its return loss at the center frequency is $12.3 \mathrm{~dB}$ while the return loss of the proposed antenna is $21 \mathrm{~dB}$. So the size as well as the return loss of the proposed patch antenna in this paper are far better than [31].

\section{DESIGN AND FABRICATION OF THE PROPOSED ANTENNA}

The three selections to be made before designing of a patch antenna are frequency of use, dielectric material, thickness of dielectric substrate. The chosen values for this design are $1115 \mathrm{MHz}$, Ceramic material and $1.5 \mathrm{~mm}$ respectively. The dimensional magnitudes for rectangular patch are calculated employing Equations (1-7) from [1]. The optimal parameters are listed in Table 1. The pictorial view of designed antenna is displayed in Fig. 4. The conducting layers of the antenna are made of copper having thickness of $0.035 \mathrm{~mm}$. Microstrip inset line feeding mechanism was implemented due to easy fabrication and better matching behavior. Reduced ground structure has been implemented to enhance the performance of the antenna [14]. Both the feed line and the patch itself are kept a bit off center as clear from given values of dimensions. The basic design formulas are expressed as Equations (1-7) 


$$
\begin{aligned}
& \mathrm{w}=\frac{\mathrm{c}}{2 \mathrm{f}_{\mathrm{o}} \sqrt{\frac{\left(\varepsilon_{\mathrm{r}}+1\right)}{2}}} \\
& \varepsilon_{\text {reff }}=\frac{\varepsilon_{\mathrm{r}}+1}{2}+\frac{\varepsilon_{\mathrm{r}}+1}{2}\left\{\frac{1}{\sqrt{1+12 \mathrm{~h} / \mathrm{w}}}\right\} \\
& \mathrm{L}_{\text {eff }}=\frac{\mathrm{C}_{\mathrm{o}}}{2 \mathrm{f}_{\mathrm{o}} \sqrt{\varepsilon_{\text {reff }}}} \\
& \Delta \mathrm{L}=0.412 \mathrm{~h} \frac{\left(\varepsilon_{\text {reff }}+0.300\right)\left(\frac{\mathrm{w}}{\mathrm{h}}+0.264\right)}{\left(\varepsilon_{\text {reff }}-0.258\right)\left(\frac{\mathrm{w}}{\mathrm{h}}+0.813\right)}
\end{aligned}
$$

$\mathrm{L}_{\text {eff }}=\mathrm{L}-2 ? \mathrm{~L}$

$\mathrm{Lg}=6 \mathrm{~h}+\mathrm{L}_{\mathrm{eff}}$

$\mathrm{Wg}=6 \mathrm{~h}+\mathrm{W}$

The Fig. 4 explains the dimensions of the various parameters of the fabricated antenna. The length and the width of the substrate are 26.5 and $20.5 \mathrm{~mm}$ respectively. The length of the partial ground is $26.5 \mathrm{~mm}$ which is equal to the length of the substrate but its width is $8 \mathrm{~mm}$ only. Similarly, the length and the width of the patch of this fabricated design are 22 and $17.5 \mathrm{~mm}$ respectively. The high substrate material has reduced the size of the antenna.

TABLE 1. DIMENSIONAL VALUES OF ANTENNA MM)

\begin{tabular}{|c|c|c|c|}
\hline Dimensions & Value & Dimensions & Value \\
\hline Substrate Length (Lg) & 20.5 & Patch Length (L) & 17.5 \\
\hline Substrate Width (Wg) & 26.5 & Patch Width (W) & 22 \\
\hline Feed Line Length & 8 & Right Arm Length & 8.5 \\
\hline Feed Gap & 1 & Left Arm Length & 9.5 \\
\hline Feed Line Width & 2 & Ground Length & 8 \\
\hline Bottom Gap (Patch and Substrate) & 2 & Ground Width & 20.5 \\
\hline Upper Gap (Patch and Substrate) & 1.5 & Right Gap (Patch and Substrate) & 2.5 \\
\hline
\end{tabular}
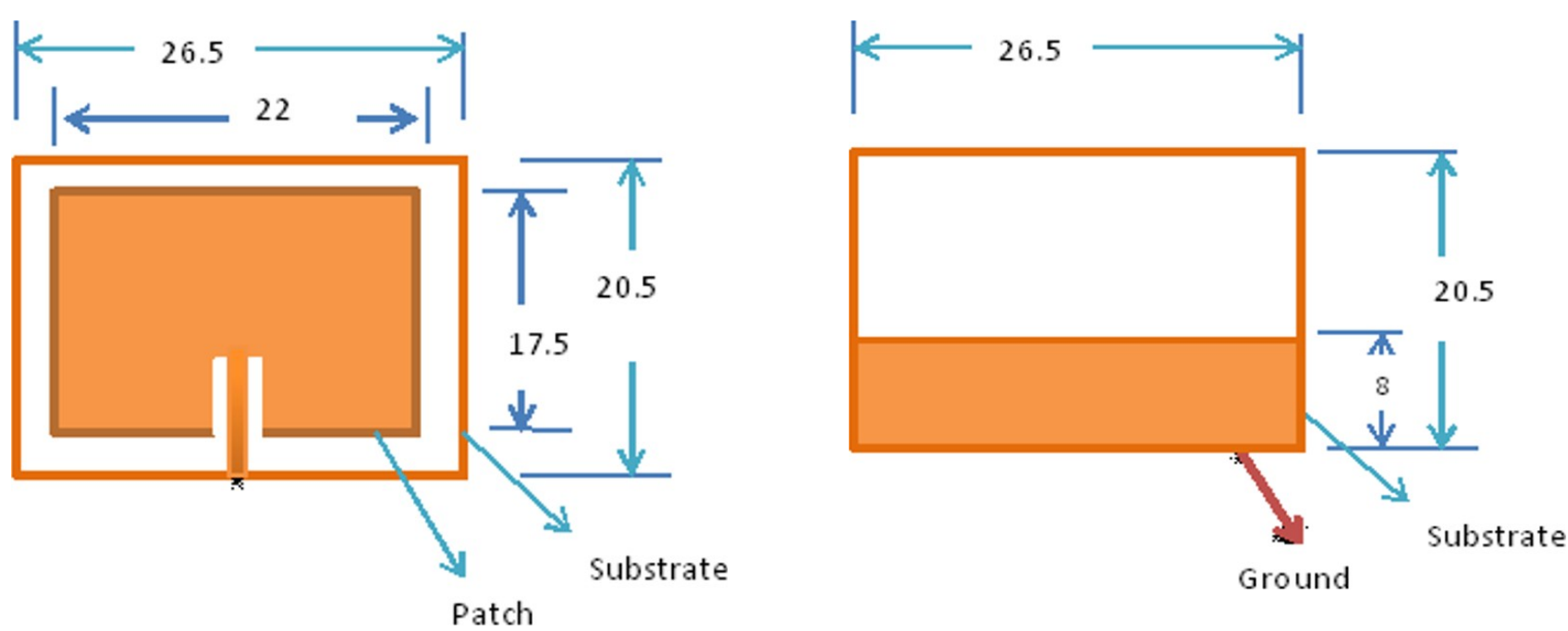

Ground

FIG. 4. PICTORIAL VIEW OF PROPOSED ANTENNA (MM) 


\section{RESULTS AND ANALYSIS}

Important performance characteristics of the fabricated antenna were experimentally investigated using Vector Network Analyzer. Bandwidth, VSWR, Return Loss and Input Impedance were measured and are briefed given in Table 2.

\subsection{Resonance Frequency, Bandwidth and Return Loss}

The antenna resonated at a frequency of $1154 \mathrm{MHz}$ in Lband region. The scattering parameter as measured is depicted in Fig. 5. It is clear from the result that $-10 \mathrm{~dB}$ resonance starts from $1070 \mathrm{MHz}$ and goes up to 1256 $\mathrm{MHz}$ covering a frequency range of $186 \mathrm{MHz}$. Thus, the bandwidth offered by the antenna is $186 \mathrm{MHz}(16.11 \%)$. The return loss at central resonant frequency is $21.10 \mathrm{~dB}$. Due to the use of high permittivity substrate material the small sized patch has presented resonance at a low frequency in L-band. Three frequencies of the bandwidth that are lower frequency, center frequency and upper frequency are very important. The lower frequency of the BW which corresponds to the return loss of $-10 \mathrm{~dB}$ is $1070 \mathrm{MHz}$, the center frequency is $1145 \mathrm{MHz}$ and the upper frequency which corresponds to the return loss of $-10 \mathrm{~dB}$ as well is $1256 \mathrm{MHz}$.

\subsection{Voltage Standing Wave Ratio}

The VSWR graph is shown in Fig. 6. In the whole frequency range of the antenna, the VSWR remains below the tolerable value of 2 . The minimum value of VSWR is 1.19 which is present at the central frequency of resonance.

\subsection{Smith Chart and Antenna Impedance}

The smith chart is a pictorial view of the antenna impedance for the frequency range. The impedance changes with the change in frequency. For the operating $-10 \mathrm{~dB}$ frequency range of the fabricated antenna the measured smith chart is displayed in Fig. 7. The input impedance of the antenna is $45.3+\mathrm{j} 6.89 \Omega$ at resonant frequency. It shows that the antenna is better matched with the transmission line impedance of $50 \Omega$. Figs. 8-9 show the photographs of the fabricated antenna and the measurement setup.

The pictorial view of the patch and the truncated ground of the fabricated antenna are displayed in Figs. 8-9.

\section{TABLE 2. MEASUREMENT RESULTS OF THE FABRICATED ANTENNA}

\begin{tabular}{|c|c|c|c|c|c|}
\hline $\begin{array}{c}\text { Resonance Frequency } \\
(\mathrm{MHz})\end{array}$ & $\begin{array}{c}\text { Bandwidth } \\
(\mathrm{MHz})\end{array}$ & $\begin{array}{c}\text { Bandwidth } \\
(\%)\end{array}$ & $\begin{array}{c}\text { Return Loss } \\
(\mathrm{fr})\end{array}$ & $\begin{array}{c}\text { VSWR } \\
(\mathrm{fr})\end{array}$ & $\begin{array}{c}\text { Input Impedance } \\
(\mathrm{fr})\end{array}$ \\
\hline 1154 & $\begin{array}{c}186 \\
(1070-12546)\end{array}$ & 16.11 & $-21.10 \mathrm{~dB}$ & 1.19 \\
\hline
\end{tabular}

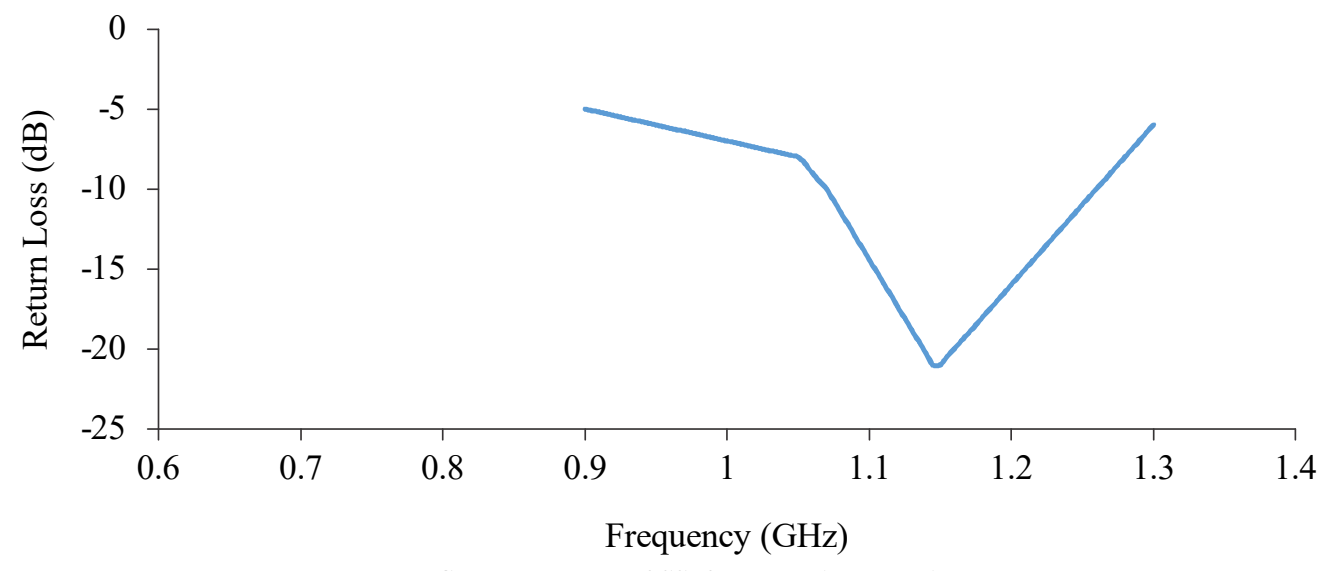

FIG. 5. RETURN LOSS OF THE ANTENNA 


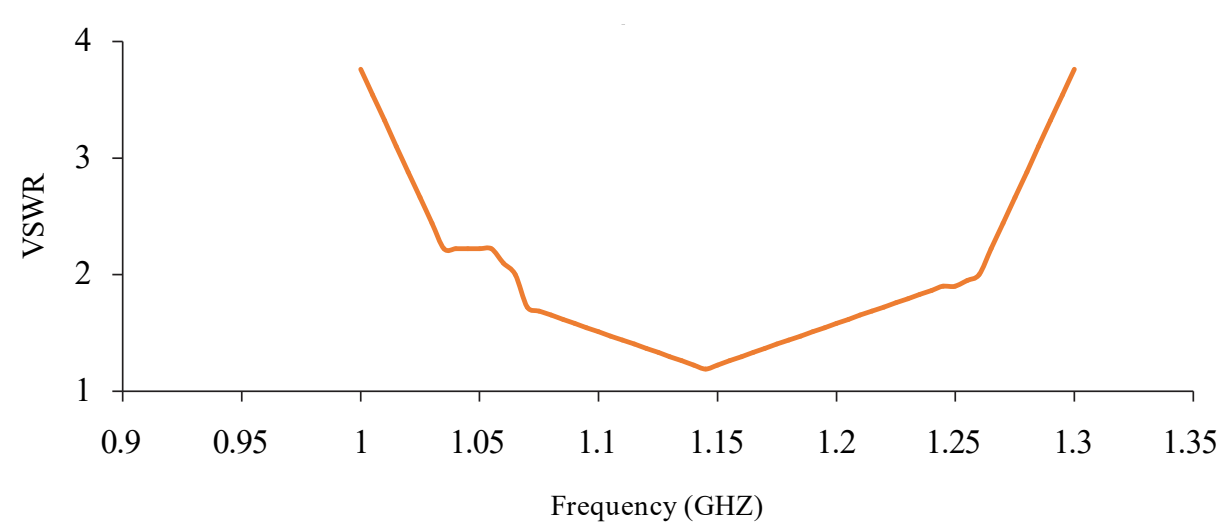

FIG. 6. VSWR OF THE ANTENNA

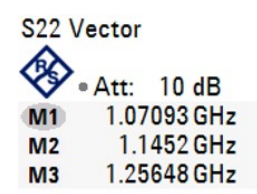
RBW: $10 \mathrm{kHz}$ SWT: Auto
$29.3-j 14.0 \Omega$
$45.3+j 6.89 \Omega$
$95.1-\mathrm{j} 6.83 \Omega$

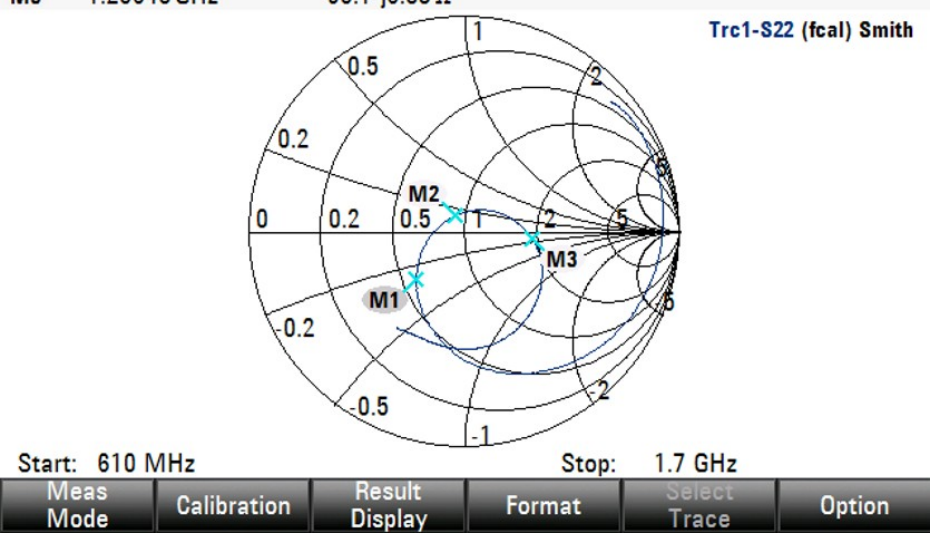

13/04/18 09:29 मt:

Trace: Clear/Write

Suppr: Off

Trc1-S22 (fcal) Smith

FIG. 7. SMITH CHART
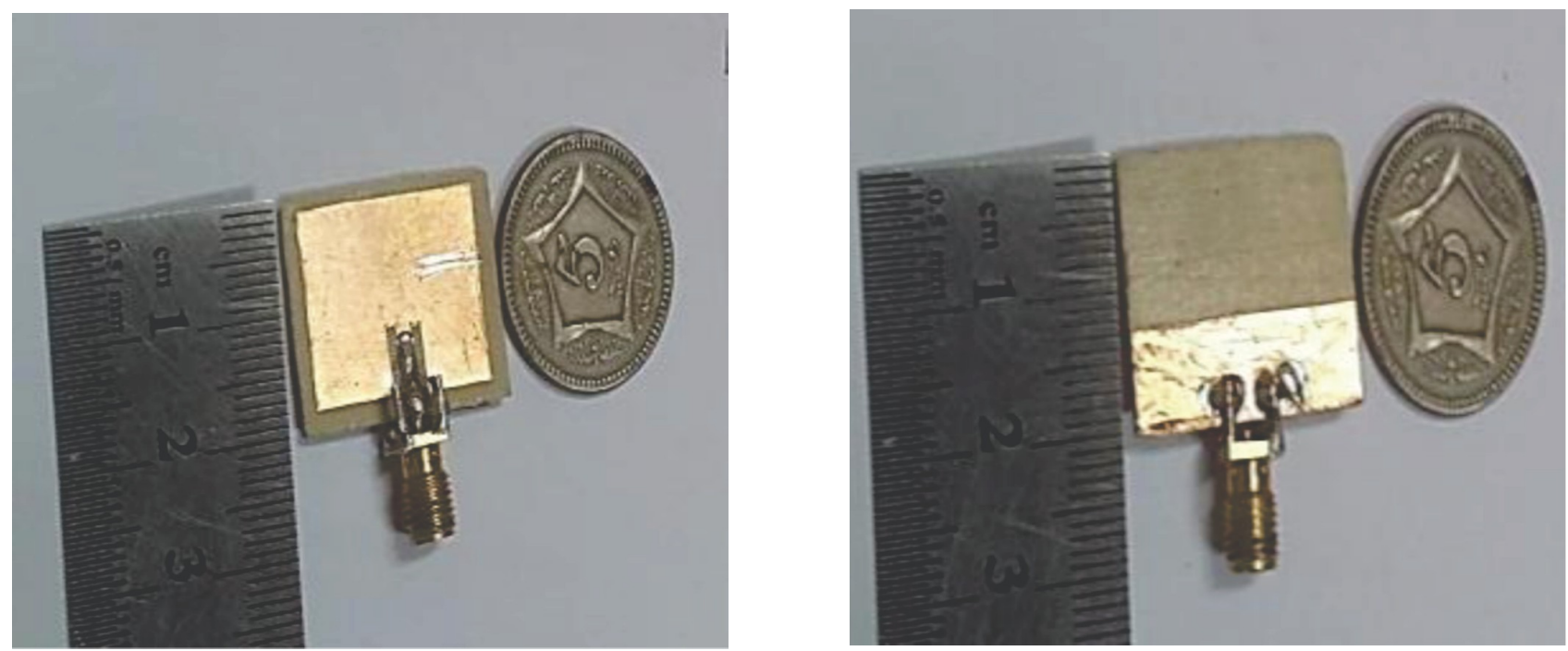

FIG. 8. FABRICATED ANTENNA VIEWS AND TESTING SETUP

Mehran University Research Journal of Engineering \& Technology, Volume 38, No. 4, October, 2019 [p-ISSN: 0254-7821, e-ISSN: 2413-7219] 


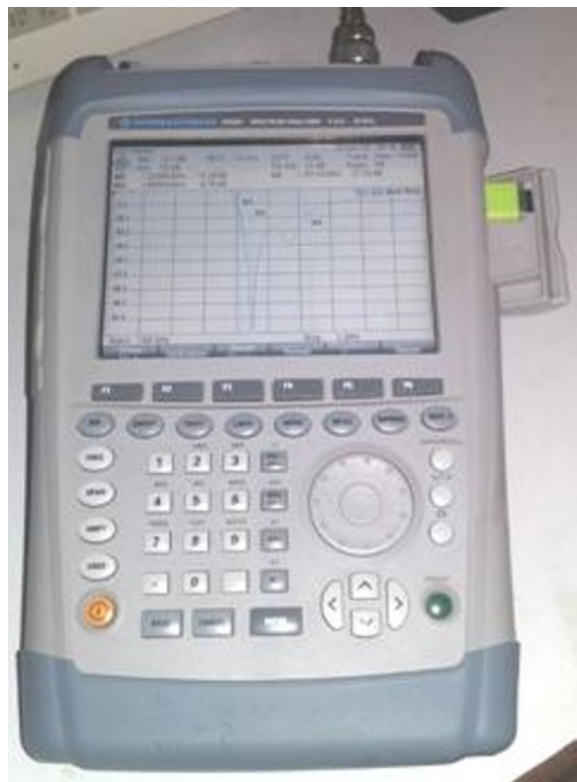

FIG. 9. VECTOR NETWORK ANALYZER USED FOR TESTING PURPOSES

\subsection{Comparison with other Designs}

The antenna fabricated for L-band application has much reduced size as compared to those available in literature [24-31].

\section{CONCLUSION}

Experimental investigation of a novel compact rectangular patch antenna loaded with a locally synthesized high permittivity ceramic was carried out. The miniature antenna may be used for the desired resonant frequency resonated in L-band. The size of the antenna has been drastically reduced for such a low frequency due to loading of novel material. High permittivity materials are not available; however, these may be synthesized by preparing different composition of ceramic materials. The concept was introduced that small sized patch antennas may be realized using these ceramics. This antenna is a better candidate for low earth orbit satellites, GPS and other aeronautical and maritime wireless communications.

\section{ACKNOWLEDGMENT}

The authors acknowledge the University of Engineering \& Technology Peshawar, and Federal Urdu University of Arts, Science \& Technology, Karachi, Pakistan, provided the testing facilities for the research work.

\section{REFERENCES}

[1] Balanis, C.A., “Antenna Theory: Analysis and Design”, 2nd Edition, John Willey and \& Son, Inc., 1997.

[2] James, J.R., Hall, P.S., and Wood, C., ”Microstrip Antenna Theory and Design", Peter Peregrinus, 1981.

[3] www.antenna-theory.com

[4] www.orbanmicrowave.com

[5] Sandeep, B.S., and Kashyap, S.S., "Design and Simulation of Microstrip Patch Array Antenna for Wireless Communication at 2.4GHZ", International Journal of Scientific \& Engineering Research, Volume 3, No. 11, [ISSN: 2229-5518], November, 2012.

[6] https://www.google.com.pk/url?sa=i\&source=images\&cd $=\& \mathrm{cad}=$ rja $\&$ uact $=8 \& \mathrm{ved}=2 \mathrm{ahUKEwjf} 8$ onf $96 \mathrm{HeAhU}$ EyaQKHR1pDn4QjRx6BAgBEAU\&url=https\%3A\%2 F\%2Fwww.researchgate.net $\% 2 F$ figure $\% 2$ FNature-ofelectric-field-when-a-patch-antenna-radiatesmicrowaves_fig1_273244385\&psig=AOvVaw 11 ZGhoGVSK1WeZB6eG8cE8\&ust=1540568604178140

[7] https://www.google.com.pk/url?sa=i\&source=images \& $\mathrm{cd}=\& \mathrm{cad}=\mathrm{rja} \& \mathrm{uact}=8 \& \mathrm{ved}=2 \mathrm{ahUKEwijqP} \_\mathrm{f}-$ aHeAhXD-aQKHSWXCywQj Rx6BAgBEAU\&url=http $\% 3 \mathrm{~A} \% 2 \mathrm{~F} \% 2 \mathrm{Fwww}$.urel.feec.vutbr.cz $\% 2 \mathrm{~F} \sim$ raida $\% 2 \mathrm{Fmulti}$ media\%2Findex.php\%3Fnav\%3D4-7-A\%2 6lang\%3 Den\&psig=AOvVaw2zSqOOjOVzL331TvwJ4gK\& ust $=154056922336234$

[8] Civerolo, M. “Aperture Coupled Patch Antenna Design Methods", MS Thesis., California Polytechnic State University, 2011.

[9] Garg, R., Bhartia, P., Bahl, I., and Ittipiboon, A., "Microstrip Antenna Design Handbook", Artech House, Boston 2001.

[10] Herscovici, N., "New Considerations in the Design of Microstrip Antennas", IEEE Transactions on Antennas and Propagation, Volume 6, pp. 807-812, Jun. 1998. 
[11] Ranjan, M., "An Overview of Microstrip Antenna", HCTL Open International Journal of Technology Innovations and Research, http://ijtir.hctl.org Volume 21, No. 2, [e-ISSN: 2321-1814, ISBN (Print): 978-81932623-1-3], August, 2016.

[12] Abdelaziz, A.A., "Bandwidth Enhancement of Microstrip Antenna”, Progress in Electromagnetics Research, Volume 63, pp. 311-317, 2006.

[13] Patil, A., and Suryakanth, B. "A Survey and Review on Gain Enhancement Methods of Microstrip", International Journal on Emerging Technologies (Special Issue on NCRIET-2015) Volume 6, No. 2, pp. 98-104, [ISSN (Print): 0975-8364, ISSN (Online)], 2015.

[14] Arya, A.K., Machavaram, K., Patnaik, A., "On the Size Reduction of Microstrip Antenna with DGS", 35th InternationalConference on Infrared, Millimeter, and Terahertz Waves, [DOI: 10.1109/ICIMW.2010.5612948], September, 2010.

[15] Gaikwad, S.S., Singh, M., Ajey, A., and Karthikayen, S.S., "Size Miniaturized Fractal Antenna for $2.5 \mathrm{GHz}$ Application”, IEEE Students' Conference on Electrical Electronics and Computer Science, pp. 1-4, 2012.

[16] Fong, L.K., and Chair,R., "On the Use of Shorting Pins in the Design of Microstrip Patch Antennas", HKIE Transactions, Volume 11, No. 4, 2004.

[17] Trippe, A., and Bhattacharya, S., "Compact Microstrip Antennas on a High Relative Dielectric Constant Substrate at $60 \mathrm{GHz}$, IEEE International Symposium on Antennas and Propagation, pp. 519-520 [DOI: 10.1109/APS.2011.5996759]. 2011

[18] Sang, H.W., Lee, Y.S., and Yook, J.G. "Wideband Microstrip Patch Antenna with U-Shaped Parasitic Elements", IEEE Transactions on Antennas and Propagation, Volume 55, pp. 1196-1199, 2007.

[19] Hwang,Y., Zhang,Y.P., and Lo,T.K., "Probe-Fed Microstrip Antennas Loaded with Very High-Permittivity Ceramics: Research Articles", International Journal of RF and Microwave Computer-Aided Engineering, Volume 16, No. 5, pp. 454-462 John Wiley and Sons Ltd. Chichester, UK, September, 2006.

[20] Kaur, G., and Goyal, E.S., "To Study the Effect of Substrate Material for Microstrip Patch Antenna", International Journal of Engineering Trends and Technology, Volume 36, No. 9, June, 2016.
[21] Rakholiya, A.A., and Langhnoja, N.V., “A Review on Miniaturization Techniques for Microstrip Patch Antenna", International Journal Advanced Research and Innovative Ideas in Education, Volume 3, No. 2, 2017.

[22] Singh A.K., AbegaonkarM.P., and KoulS. K., "Miniaturized Multiband Microstrip Patch Antenna Using Metamaterial Loading for Wireless Application" Progress in Electromagnetics Research C, Volume 83, pp. 71-82, 2018.

[23] Ali, A., Jawaid, M.M.,Pirzada, N., Memon, S.A.,’Design and Simulation of a Rectangular E-Shaped Microstrip Patch Antenna for RFID based Intelligent Transportation", International Journal of Advanced Computer Science and Applications, Volume 9, No. 4, 2018

[24] Singh, A., Singh, J.S., and Kaur, K., "Multiband Hybrid Microstrip Patch Antenna for L, S and C Band Applications", International Journal of Control Theory and Applications, Volume 10, [ISSN: 0974-5572], November, 2017.

[25] Poonkzhali, R., Thiripurasundari, D., Alex, Z.C., and Balakrishnan, T., "Compact Printed Dipole Antenna for L- Band Radar Applications", International Journal on Communications Antenna and Propagation, Volume 5, No. 4, 2015.

[26] Latrach, M., and Islam, S., "Small Broadband Patch Antenna Design for L-Band Applications", $32^{\text {nd }}$ General Assembly and Scientific Symposium of the International Union of Radio Science, pp. 1-3, Montreal, QC, 2017.

[27] Koulouridis, S., "L-Band Circularly Polarized Small Aperture Thin Textured Patch Antenna", IEEE Antennas and Wireless Propagation Letters, Volume 7, pp. 225228, February, 2008.

[28] Kumar, A., "Design, Fabrication and Comparison of Microstrip Antennas for L-Band Applications", International Journal of Science Technology \& Engineering, Volume 2, No. 3, September, 2015.

[29] Rajendran, J., Peter, R., and Soman, K., "Design of Circular Polarized Microstrip Patch Antenna for L Band", International Journal of Electronics Signals and Systems, Volume 1, No. 3, [ISSN: 2231-5969], 2012.

[30] Babu, K.T., Nannepaga, B., Rao, K.P.K., "Design of Dual Polarized Reconfigurable Patch Antenna for LBand Applications", International Journal of Engineering Science \& Advanced Technology, Volume 7, No. 2, pp. 190-196, [ISSN: 2250-3676], March-April, 2017.

[31] Malisuwan, S., Tiamnara, N., and Suriyakrai, N., "Design of Dual-Band Circular Microstrip Patch Antenna for LBand Military Applications", International Journal of Information and Electronics Engineering, Volume 6, No. 1, January, 2016. 